\title{
Analysing Barriers to Accessing Maternal Healthcare Systems in Developing Countries: A Case of Sokoto-Northern Nigeria
}

\author{
Muazu Alhaji Shamaki ${ }^{*}$ \\ Vivien W.C. Yew² \\ Muhammad Kabiru Dahiru \\ ${ }^{1}$ Department of Geography, Usmanu Danfodiyo University, Sokoto-Nigeria \\ ${ }^{2}$ School of Social, Development and Environment Studies, Faculty of Social Sciences and Humanities, \\ Universiti Kebangsaan Malaysia \\ ${ }^{3}$ Department of Geography and Planning,University of Jos-Nigeria. \\ *Corresponding Author Email: mashamakisa@udusok.edu.ng
}

Doi:10.5901/mjss.2017.v8n1p299

\begin{abstract}
The government and other policy makers continue struggles to achieve maximum access of modern healthcare by the women in developing countries. To assist actualising such goal this study intends to examine the influence of distance to facility, time taken for travel and means of transportation (DTTf) to the health facility. Based on conceptual discussion of Behavioural Model of Health Services' Use, over 300 targeted women aged 15 to 45 years were selected using systematic sampling in three regions of Sokoto, northern Nigeria and IBM-SPSS version 22 statistical software program was employed for data analysis in both descriptive statistics and Pearson $r$ correlation analysis. The finding reveals that over 77 percent women are located far away distance from health facility, 2.2percent take over 5 hours of traveling before they can reach to the health centre and 35 percent of women use hired motor-cycle. Also, there is strong significant relationship between antenatal care services and distance $(r=0.477$ and $p .<.40)$ correlation significant at 0.05 (2-tailed) as well as the between delivery care and PNC services. To achieve maximum women access to healthcare, relevant information aimed at proper planning for distribution of health facilities, have been provided for both government and other policy makers in developing countries.
\end{abstract}

Keywords: women, health care, access to facilities, antenatal care, delivery care, postnatal care, Sokoto state.

\section{Introduction}

This study examines distance, time and transportation factors (DTTf concept) in seeking for antenatal care (ANC), skilled delivery (DC) and postnatal care services (PNC) by women. A number of studies in Nigeria have shown how the interaction between physical, social, economic and health system factors accounted for low utilization of maternal health services (see, for example, Okposio et al. 2012; Ononokpono 2013; Owumi and Raji 2013; and Shamaki and Buang 2014). While access to health care services provides the opportunity to use health services (Keya et al., 2013); distances and unavailability of means of transport, out-of-pocket payments for maternal care or course of drugs, and long queues are some of the barriers attributed to poor maternal health access. Based on WHO (2010) report, and Frenz and Vega (2010), these access hurdles are not peculiar to Nigeria; they are also experienced elsewhere in low-and-middle-income countries (LMICs). However, Ononokpono (2013) added that geographic conditions of places are an important barrier as it reflects the location where women reside, which can also influence their health behaviour.

Technological conditions, such as means of transport and mass media in the community, organisational conditions and religious affiliation, are having profound influence on women's decisions to seek maternal healthcare services. Distance to health facility acts as a disincentive to seeking care and obstacle to reaching health facility. In view of that, most pregnant women do not even attempt to reach facility especially for delivery, since it is difficult to walk long distances during labour. Access does not only means visiting a medical care provider, but also getting to the right services at the right time to promote improved health outcomes (Andersen et al. 2011). Thus, healthcare access is the actual use of personal health services and everything that facilitates or impedes their use. It is the relationship between health services systems and the populations they serve (Pacagnella et al. 2012). Hence, living in a village area with no transport available is associated with phase II of the "Three Delays Model" developed by Thadeus and Maine (1994). The 
model comprises delay in deciding to seek care (Phase I), delay in reaching care facility (Phase II) and delay in receiving adequate health care services (Phase III). This model has proven useful to researchers in analysing maternal deaths (Waiswa et al. 2010; Mbaruku et al. 2009). In this study, this link simply means DTTf concept. To confirm the relationship, Ononokpono (2013) have shown that the urban poor had a significantly lower risk of home delivery than rural residents.

According to Jafarey and Korejo (1995), the unavailability of transport and lack of finances were the economic reasons why families are hesitant about going to hospital, and even when a woman decides to seek care at an appropriate time, she may face barriers of transport or long distance to a facility (Pacagnella et al. 2012). Owumi and Raji (2013) emphasize distance of the hospital from residential homes makes accessibility very difficult. Okposio et al. (2012) lamented that transportation cost, distance to health facilities and perceived loss of working time are factors that may influence access to health services in the developing countries. Hence, this study seeks to explore on these basic barriers influencing the women's healthcare facilities utilisations in Sokoto-Nigeria, and provides primary information on these factors based on descriptive and Pearson correlation analysis. The study is limited to the three basic physical barriers; distance to health facilities, time taken and means of transport available for the women folk, which are referred to as DTTf concept.

\section{Conceptual Discussion}

This study is organised based on the Behavioural Model of Health Services Use reviewed by Andersen (1995). The model (Andersen 1995: 1) was originally developed in the late 1960s to facilitate the understanding of why families use health services; to define and measure equitable access to health care; to facilitate and develop policies that promote equitable access. In furtherance to Andersen's (1995: 1- 3) opinion, any extensive effort in looking at health services' use must take into consideration how people view their own general health and functional state, as well as how people experience symptoms of illness, pain, and worries about their health and whether or not they judge their problems to be sufficiently important and severe to seek medical help. The author added that both community and personal enabling factors must be present for the use of health services to take place. First, health personnel and facilities must be available where people live and work. Second, people must have the means and know-how to get to those services and make use of them.

Income, health insurance, a regular source of care, means of traveling and waiting times are some of the enabling factors due for more considerations in health services' use at any geographical area. To complement Andersen's (1995) enabling factors to health services' use, Arcury et al. (2005) identified transportation as another enabling factor to health services. In their study in rural North Carolina, a very small percentage of residents surveyed had used public transportation to access health care. The measure of transportation by Arcury et al. included distance and activity space, of which activity space refers to places or areas an individual travels to, on a frequent basis. Therefore, combining both behavioural model of health services' use by Andersen (1995) and partial research findings of Arcury et al. (2005), this study, which focuses on distance, time and transportation factors (DTTf concept) in accessing maternal healthcare systems, provides relevant findings and information to improve access to health facilities among women in developing countries.

\section{Methods}

This study uses primary data collected using an instrument questionnaire in Sokoto state, Nigeria. Over 315 married women aged 15 to 45 years old were selected for questionnaire response in order to analyse DTTf for accessing women healthcare services. A systematic sampling design was used to select respondents from the sampling frame of the study population. An IBM-SPSS version 22 statistical software program was employed for the analysis of data and both descriptive statistics and Pearson $r$ correlation were conducted. The correlation expresses the extent to which two or more variables vary together to test the relationships between DTTf concept and women healthcare utilisations. The study was conducted across maternal and child health care centres from three areas of Sokoto state, namely Isa, Sokoto and Tambuwal. The choice of these areas is to have equal representation of the three geopolitical zones in the state couple with high rate of maternal deaths recorded in rural areas of Tambuwal and Isa local governments and the study was carried out between October 2013 and March 2014. Ethical issues explored in the research are in line with and not limited to Wiles et al. (2005) and Flick (2009) recommend in collecting data from participants. Thus, informed consent was obtained from participants, permissions and approvals were also granted by the Ministry of Health Sokoto state and the administrative authorities that include Hospital Service Management Board (HSMB) Sokoto state. For example, to obtain the participants' informed consent, they were informed about the purpose of the research, that their privacy would 
be protected, their participation is voluntary, they have the right to withdraw at any time, and assured of confidentiality and anonymity. Most importantly, certain peculiar issues of gender, religion and culture of Sokoto were taken into account.

\section{Results}

\subsection{Descriptive analysis}

Table 1: Distance to health centre

\begin{tabular}{ccccc}
\hline Distance & Frequency & Percent & Valid Percent & Cumulative Percent \\
\hline$\leq 0-10 \mathrm{~km}$ & 74 & 23.5 & 23.5 & 23.5 \\
$11-20 \mathrm{~km}$ & 85 & 27.0 & 27.0 & 50.5 \\
$21-30 \mathrm{~km}$ & 97 & 30.8 & 30.8 & 81.3 \\
$31 \mathrm{~km} \geq$ & 59 & 18.7 & 18.7 & 100.0 \\
Total & 315 & 100.0 & 100.0 & \\
\hline
\end{tabular}

Analysis of Table 1 above indicates that majority (30.8\%) cover a distance of 21-30km to the nearest health centre. And, in a situation where women walk for a long distance reflects why there is low utilisation of women health care facilities. The least number (59) of respondents cover a distance of 31 and above kilometres, while $23.5 \%$ of women are within the shortest distance of $\leq 0-10 \mathrm{~km}$. However, further observation reveals that even those that are within the shortest distance still found very difficult to obtain health services from the centres due to difficulty and cost of using hired motorcycle (kabu-kabu) - a common means of transportation using tricycles. As such any distance above 10 kilometres is considered to be far. Taking into account this group of women respondents, $77 \%$ of them cover more than 10 kilometres to reach health centres. Thus, physical barriers, such as distance travel and the time taken greatly hinders many women from obtaining modern health services which consequently bring about low utilisation of maternal health care facilities.

The second factor of the DTTf concept is the time taken to reach health facility and, irrespective of the forms of transportation, the time taken, which varies in different places, significantly affect access to health facilities. Findings indicate that a substantial proportion of $31.4 \%$ women take 1 to 2 hours from their respective houses to obtain services at the closest health centre. This is closely followed by $30.5 \%$ of the respondent that covers 30 minutes to 1 hour, while only $25.4 \%$ are within the shortest time of less than or equal to 30 mins of travelling to the health centre. However, $10.5 \%$ of them take 3-4hours, while the least number of 7 women or $2.2 \%$ take the longest time of 5 hours and above. This is so tedious that if a woman attended once, she will never want to return again. Figure 1 below shows the time taken and the percentage of respondent.

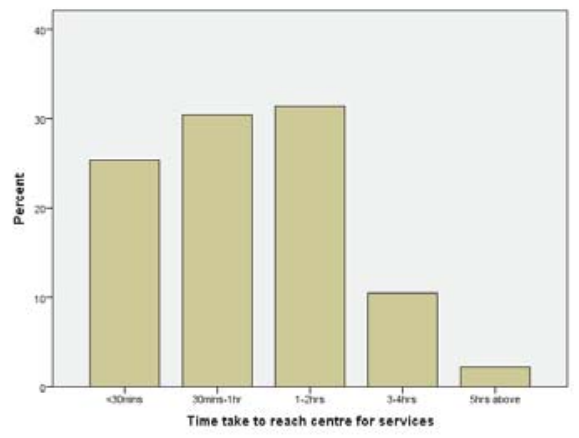

Figure 1. Time taken to reach health centres

As an integral factor influencing health services utilisation, various means of transportation in the area include family cars, commercial cars, hired motor cycles and others unspecified. And, the result shows that $35 \%$ of the women use kabukabu, despite their pregnancy conditions. Since many women add weight particularly during the pregnancy, this is a serious problem when using kabu-kabu transport which makes them find it very difficult and uncomfortable for accessing 
health centres. Similarly, the analysis shows $29 \%$ of respondents use unspecified forms of transportation that largely involved trekking and use of animal to obtain services. However, only $24 \%$ of the respondents use family cars while about $12 \%$ use taxis. The general scenario indicated here means that only $24 \%$ that use family car have better chances of health facilities utilisation among women. Figure 2 below shows the diagrammatic presentation of means of transportation among women.

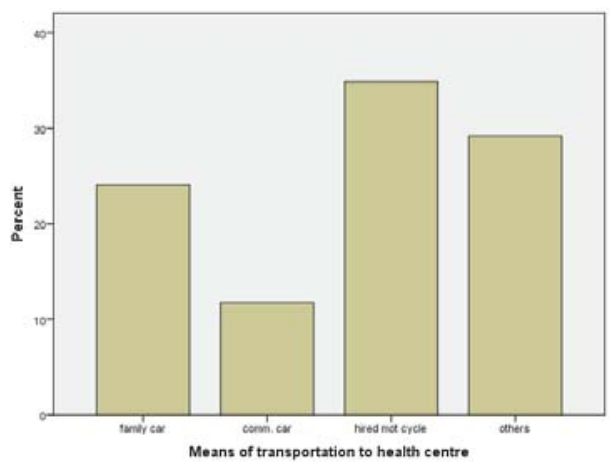

Figure 2: Means of transportation to the health centre

\subsection{Pearson r correlation analysis}

Table 2. Antenatal care services and the physical factors

\begin{tabular}{|c|c|c|c|c|c|}
\hline & & $\begin{array}{c}\text { Antenatal care (ANC) } \\
\text { services }\end{array}$ & $\begin{array}{l}\text { Distance to health } \\
\text { centre }\end{array}$ & $\begin{array}{l}\text { Time taken to } \\
\text { health centre }\end{array}$ & $\begin{array}{c}\text { Means of } \\
\text { Transportation }\end{array}$ \\
\hline \multirow{3}{*}{$\begin{array}{l}\text { Antenatal care } \\
\text { (ANC) services }\end{array}$} & Pearson Correlation & 1 & $.477^{\star}$ & .086 & -.011 \\
\hline & Sig. (2-tailed) & & .040 & .127 & .843 \\
\hline & $\mathrm{N}$ & 315 & 315 & 315 & 315 \\
\hline \multirow{3}{*}{$\begin{array}{l}\text { Distance to health } \\
\text { centre }\end{array}$} & Pearson Correlation & $.477^{\star}$ & 1 & $.515^{\star \star}$ & .077 \\
\hline & Sig. (2-tailed) & .040 & & .000 & .170 \\
\hline & $\mathrm{N}$ & 315 & 315 & 315 & 315 \\
\hline \multirow{3}{*}{$\begin{array}{l}\text { Time taken to } \\
\text { health centre }\end{array}$} & Pearson Correlation & .086 & $.515^{\star \star}$ & 1 & $.590^{* *}$ \\
\hline & Sig. (2-tailed) & .127 & .000 & & .003 \\
\hline & $\mathrm{N}$ & 315 & 315 & 315 & 315 \\
\hline Means of & Pearson Correlation & -.011 & .077 & $.590^{\star \star}$ & 1 \\
\hline \multirow[t]{2}{*}{ Transportation } & Sig. (2-tailed) & .843 & .170 & .003 & \\
\hline & $\mathrm{N}$ & 315 & 315 & 315 & 315 \\
\hline
\end{tabular}

The result shows significant relationship between antenatal care -ANC services and distance covered to health centre, $(r$ $=0.477$ and $p .=.04)$ correlation significant at $0.05(2$-tailed). There is also strong association between time-taken and the distance to the facility with $r=0.515$ and $p .<0.000$, correlation significant at 0.01 level. Lastly, the result indicates strong significant relationship between the means of transportation and time taken to reach health centre, with Pearson correlation of $r=0.590$ and $p .<0.003$ indicating correlation significant at 0.01 levels.

Table 3. Delivery care services and the physical factors

\begin{tabular}{llcccc}
\hline & $\begin{array}{c}\text { Delivery care } \\
\text { services }\end{array}$ & $\begin{array}{c}\text { Distance to health } \\
\text { centre }\end{array}$ & $\begin{array}{c}\text { Time taken to health } \\
\text { centre }\end{array}$ & $\begin{array}{c}\text { Means of } \\
\text { Transportation }\end{array}$ \\
\hline Delivery care & Pearson Correlation & 1 & -.054 & $.847^{* *}$ & $-.113^{*}$ \\
services & Sig. (2-tailed) & & .343 & .011 & .044 \\
& $\mathrm{~N}$ & 315 & 315 & 315 & 315 \\
Distance to & Pearson Correlation & -.054 & 1 & $.515^{* *}$ & .077 \\
health centre & Sig. (2-tailed) & .343 & & .000 & .170 \\
& $\mathrm{~N}$ & 315 & 315 & 315 & 315
\end{tabular}




\begin{tabular}{llcccc}
\hline & $\begin{array}{c}\text { Delivery care } \\
\text { services }\end{array}$ & $\begin{array}{c}\text { Distance to health } \\
\text { centre }\end{array}$ & $\begin{array}{c}\text { Time taken to health } \\
\text { centre }\end{array}$ & $\begin{array}{c}\text { Means of } \\
\text { Transportation }\end{array}$ \\
\hline Time taken to & Pearson Correlation & $.847^{\text {** }}$ & $.515^{\text {** }}$ & 1 & .059 \\
health centre & Sig. (2-tailed) & .011 & .000 & 315 & .300 \\
& $\mathrm{~N}$ & 315 & 315 & .059 & 315 \\
Means of & Pearson Correlation & $-.113^{*}$ & .077 & .300 & 1 \\
Transportation & Sig. (2-tailed) & .044 & .170 & 315 & 315 \\
\hline
\end{tabular}

For the delivery care, the results in table 3 shows there is significant relationship $(r=-113, p .<0.044)$ with correlation significant at the 0.05 level (2-tailed) between skilled delivery and means of transportation to the facility. There is strong association ( $r=0.515, p .<0.000$, significant at 0.01 levels) between distance to health facility and time of reaching to the facility for services. Similarly, the results shows a strong association with $r=0.847, p .<0.011$, correlation significant at 0.01 level (2-tailed) between skilled delivery services and time taken to the health facility. These findings are in line with Bakare's (2011) assertion that accessibility factors (cost, distance, transport, availability of health facilities, and nurses' attitudes) were major barriers in seeking maternal health care services. This implies that, far distances and time taken to reach the facility forms a greater obstacle in obtaining delivery care services by women in Sokoto state. Hence, most of the women deliver at home.

Table 4. Postnatal care services and the physical factors

\begin{tabular}{|c|c|c|c|c|c|}
\hline & & $\begin{array}{l}\text { Postnatal care } \\
\text { services }\end{array}$ & $\begin{array}{l}\text { Distance to health } \\
\text { centre }\end{array}$ & $\begin{array}{l}\text { Time } \\
\text { taken }\end{array}$ & $\begin{array}{c}\text { Means of } \\
\text { Transportation }\end{array}$ \\
\hline \multirow{3}{*}{$\begin{array}{l}\text { Postnatal care } \\
\text { services }\end{array}$} & Pearson Correlation & 1 & $-.095^{\star}$ & -.053 & $-.761^{*}$ \\
\hline & Sig. (2-tailed) & & .031 & .348 & .027 \\
\hline & $\mathrm{N}$ & 315 & 315 & 315 & 315 \\
\hline \multirow{3}{*}{$\begin{array}{l}\text { Distance to } \\
\text { health centre }\end{array}$} & Pearson Correlation & $-.095^{*}$ & 1 & $.515^{* k}$ & .077 \\
\hline & Sig. (2-tailed) & .031 & & .000 & .170 \\
\hline & $\mathrm{N}$ & 315 & 315 & 315 & 315 \\
\hline \multirow[t]{3}{*}{ Time taken } & Pearson Correlation & -.053 & $.515^{\text {*k }}$ & 1 & .059 \\
\hline & Sig. (2-tailed) & .348 & .000 & & .300 \\
\hline & $\mathrm{N}$ & 315 & 315 & 315 & 315 \\
\hline Means of & Pearson Correlation & $-.761^{*}$ & .077 & .059 & 1 \\
\hline \multirow[t]{2}{*}{ Transportation } & Sig. (2-tailed) & .027 & .170 & .300 & \\
\hline & $\mathrm{N}$ & 315 & 315 & 315 & 315 \\
\hline
\end{tabular}

In terms of postnatal care services table 4 the result shows there is strong significant relationship $(r=-0.095, p .<0.031)$, with correlation significant at the 0.05 level existing between postnatal care services and distance to the centre by women. This is why women in the urban areas with health facilities are more advantageous compared to those in rural areas. This implies that most respondents in the study area do not seek postnatal care services because facilities are not located close to them and hence low utilisations. There is strongest significant relationship $(r=0.515, p .<0.000$, correlation significant at 0.01 level between the distance travel and time taken to the health centre. This was as a result of the number of rural settlements accommodating large number of women. Moreover, the result also revealed that strong significant relationship with $r=0.761$ and $p .<0.027$ exist between postnatal care services and means of transportation of the area. In view of the results in this study, the distance, which is considered to be physical constraints, appears to influence all the types of maternal health services in all the regions of this study.

\section{Discussion}

The finding of this study revealed $30.8 \%$ of women cover a distance of $21-30 \mathrm{~km}$ before they reach to the closet health centre. This is too far for most of them and can make the services uninteresting. To consolidate this view, Keya et al. (2013) asserts that distance to health facility and means of transportation are major obstacles to service utilization. The finding also indicated there are about $77 \%$ of the women respondents who covers far distances of over $10 \mathrm{~km}$ from their respective residences. About 2.2\% of respondents take over 5 hours of travelling just to obtain health services at the health centre. This kind of task is considered to be tedious so much that a woman that was able to go ones will never 
wish to return again. This finding corresponds to Muchabaiwa et al. (2012) who found a woman residing in rural area is less likely to deliver at healthcare facilities than her urban counterpart due to time taken to access the facility. This could be the reason why women in the study area prefer alternative sources like herbal use and the TBA's instead of wasting long time of travelling to the facility.

In terms of transportation means, only $24 \%$ of women use family cars while the rest recourse to other means with majority (35\%) using a hired kabu-kabu to obtain health services. This finding conforms to Keya et al. (2013) who discovered that delay in reaching an obstetric medical facility is affected by the availability of transportation and road conditions. They added that transportation problem to reach an EmOC centre is common in developing countries and it contributes to pregnancy related mortalities in Gambia, Brazil, Ghana, Nigeria and Sierra Leone. The finding shows significant relationship between ANC services and distance to health centre $(r=0.477, p .=0.04)$. However in between the factors, the strongest significant association was found between distance to the facility and time-taken with $r=0.515$ and $p .<0.000$, correlation significant at 0.01 levels. This implies that both distance and time are crucial factors influencing ANC, delivery care and PNC services. In addition, it means the geographical location of facility is a significant factor determining ANC services utilisation in the study area. The finding also confirms Keya et al. (2013) that asserts the distance to a health facility plays a crucial role in health service accessibility.

This study also found strong association between skilled delivery and time to reach the facility as well as between skilled delivery and means of transportation. This corresponds to a study conducted in rural Zambia which showed skilled delivery for a birth within 1 kilometre of a comprehensive health facility are over 10 times higher for a birth whose closest facility is 20 kilometre away (Keya et al. 2013). Finally, strong significant relationship was found between postnatal care services and distance covered to the facility. So also a strong significant relationship exists between postnatal care services and means of transportation. In general these findings stressed the value of distance and means of transportation in accessing women health services. As both Keya et al. (2013) and Muchabaiwa et al. (2012) emphasised that distance between residence and health institutions are part of first and second delays to avail maternal health care service and had an influence on choice of delivery places and postnatal care service visits.

\section{Conclusion}

In order to improve access to women healthcare facilities, a DTTf concept in the region must be analysed because it is significantly associated to women health facilities utilisations; antenatal care, skilled delivery and postnatal care services. Therefore, economic aspect was not the only obstacle to accessibility because $77 \%$ of women have to cover far distance of at least 10 kilometres of travel to access health centre for services, 2.2 take a long time of over 5 hours and $35 \%$ that use hired kabu-kabu had greater chances of not accessing healthcare facilities. In addition, the finding has shown a strong significant association between the distance and time taken, which greatly determines the accessibility of such facility by the women. These findings could help for planning and policy implications in the provision and location of maternal health care facilities.

\section{Acknowledgement}

This paper was based on a field study conducted for the award of the PhD degree to the first author titled, Demographic, socio-economic and cultural analysis of health facilities utilization and maternal mortality in Sokoto state. Our sincere thanks go to Prof. Dr. Amriah Buang of the Univerisiti Kebangsaan Malaysia for supervising the thesis and the Usmanu Danfodiyo University Sokoto for financial support. We also appreciate the co-operation and approval of the Sokoto state Ministry of Health to conduct the study in the state.

\section{References}

Andersen, R. M. 1995. Revisiting the Behavioral Model and Access to Medical Care: Does It Matter? Journal of Health and Social Behavior, 36, 1-10.

Andersen, R. M. \& Davidson, P.L. 2011. Improving Access to Care in America: Individual and Contextual Indicators. DIm. Andersen, R. M., Rice, T.H. And Kominski, G.F. (pnyt.). Changing the U.S. Health Care System: Key Issues in Health Services, Policy and Management, hlm. U.S.: John Wiley \& Sons.

Arcury, T. A., Gesler, W. M., Preisser, J. S. Sherman, J. Spencer, J. and Perin, J. (2005). The Effects of Geography and Spatial Behavior on Health Care Utilization among the Residents of a Rural Region. Health Services Record, 40 (1), 135-155.

Flick, U., 2009. An Introduction to Qualitative Research. 4th edition. London: SAGE Publications Ltd

Frenz, P. and Vega, J. 2010. Universal Health Coverage with Equity: What We Know, Don't Know and Need to Know. Background paper 
for the global symposium on health systems research. Montreux, Switzerland: First Global Symposium on Health Systems Research, http://www.hsr-symposium.org/images/stories/9coverage_with_equity.pdf, accessed 4 May 2011.

Jafarey, S. N. and Korejo, R. 1995. Social and Cultural Factors Leading to Mothers Being Brought Dead to Hospital. International Journal of Gynecology \& Obstetrics 50, Supplement 2(0): S97-S99.

Keya, K., Rahman, MM, Rob, U. \& Bellows, B. 2013. Barrier of Distance and Transportation Cost to Access Maternity Services in Rural Bangladesh. Population Association of Ameria. US

Mbaruku, G., van-Roosmalen J., Kimondo I., Bilango, F. \& Bergstrom, S. 2009. Perinatal audit using the 3-delays model in Western Tanzania. International Journal of Gynaecology and Obstetrics 106(1): 85-88.

Muchabaiwa, L., Mazambani, D., Chigusiwa, L., Bindu S., \& Mudavanhu, V. 2012. Determinants of Maternal Healthcare Utilization in Zimbabwe. International Journal of Economic Sciences and Applied Research 5(2): 145-162.

Okposio, M.M., Unior, M.O. and Ukpateru, F.O. 2012. Sociodemographic Determinants of Mortality in Healthcare Centre in the Niger Delta. International Journal of Tropical Diseases and Health 2(3):173-181, 2012

Ononokpono, D. N. 2013. Determinants of Maternal Health-Seeking Behaviour in Nigeria: A Multilevel Approach. PhD Thesis, Faculty of Humanities, University of the Witwatersrand, Johannesburg.

Owumi, B. and Raji, S.O. 2013, Socio-cultural Determinants of Maternal Health Seeking Behaviour in Seme side of Benin Republic, African Journal of Social Sciences, (3): 145-158

Pacagnella, R. C., Cecatti, J. G., Osis, M. J. and Souza, J. P. 2012. The Role of Delays in Severe Maternal Morbidity and Mortality: Expanding the Conceptual Framework. Reproductive Health Matters 20(39): 155-163.

Shamaki, M. A. and Buang, A. 2014. Socio-cultural Practices in Maternal Health among Women in a Less Developed Economy: An overview of Sokoto state, Nigeria. Geografia Online Malaysia Journal of Society and Space 10(6): 1-14

Thadeus, S. and Maine, D. 1994. Too far to walk: maternal mortality in context. Social Science and Medicine 38(8): 1091-1110.

Waiswa, P., Kallander, K., Peterson, S., Tomson, G., and Pariyo, G. W. 2010. Using the three delays model to understand why newborn babies die in eastern Uganda. Tropical medicine \& international health, 15(8): 964-972.

Wall, L.L. 1998. Dead mothers and injured wives: the social context of maternal morbidity and mortality among the Hausa of Northern Nigeria. Studies in Family Planning, 29, pp. 341-359.

Wiles, R., Heath, S., Crow, G. and Charles, V., 2005. Informed consent in social science research: a literature review. NCRM Methods Review Papers NCRM/001. Southampton: Economic and Social Research Council.

World Health Organization. 2010. The World Health Report - Health Systems Financing: The Path to Universal Coverage. Geneva: World Health Organisation. 